\title{
Usefulness of aspartate aminotransferase to platelet ratio index as a prognostic factor following hepatic resection for hepatocellular carcinoma
}

\author{
MICHINORI MATSUMOTO, SHIGEKI WAKIYAMA, HIROAKI SHIBA, KOICHIRO HARUKI, \\ YASURO FUTAGAWA, YUICHI ISHIDA, TAKEYUKI MISAWA and KATSUHIKO YANAGA \\ Department of Surgery, The Jikei University School of Medicine, Tokyo 105-8461, Japan
}

Received March 31, 2018; Accepted June 12, 2018

DOI: $10.3892 /$ mco.2018.1692

\begin{abstract}
Liver function is a major prognostic factor following hepatic resection for hepatocellular carcinoma (HCC), which is well correlated with the degree of fibrosis. On the other hand, the presence of liver cirrhosis itself leads to a higher incidence of HCC than chronic hepatitis. Therefore, preoperative noninvasive markers of fibrosis are important for the assessment of prognosis for treatment of HCC. The present study aimed to analyze whether aspartate aminotransferase to platelet ratio index (APRI) could predict prognosis following hepatic resection for HCC. The subjects were 162 patients who underwent hepatic resection for HCC between January 2000 and December 2011. The relationship between APRI and disease-free and overall survival were retrospectively investigated. In multivariate analysis, indocyanine green at $15 \mathrm{~min}(\mathrm{ICG}-\mathrm{R} 15) \geq 15 \%(\mathrm{P}=0.0306)$, APRI $\geq 0.45 \quad(\mathrm{P}=0.0184)$, perioperative blood transfusion of red cell concentrates ( $\mathrm{RCC} ; \mathrm{P}=0.0034)$ and TNM stage II, III or IV $(\mathrm{P}=0.0184)$ were significant predictors in disease-free survival. For overall survival, ICG-R15 $\geq 15 \%(\mathrm{P}=0.0454)$, APRI $\geq 0.45(\mathrm{P}=0.0417)$, perioperative blood transfusion of RCC $(\mathrm{P}=0.0036)$ and TNM stage II, III or IV $(\mathrm{P}=0.0033)$ were significant predictors. In addition, higher APRI values were positively correlated with hepatitis $\mathrm{C}$ virus infection and preoperative liver function. In conclusion, APRI is an independent risk factor for disease-free and overall survival following hepatic resection for HCC.
\end{abstract}

Correspondence to: Dr Michinori Matsumoto, Department of Surgery, The Jikei University School of Medicine, 3-25-8 Nishi-shinbashi, Tokyo 105-8461, Japan

E-mail: mmatsumoto4@jikei.ac.jp

Key words: aspartate aminotransferase to platelet ratio index, liver fibrosis, liver cirrhosis, hepatocellular carcinoma, hepatic resection

\section{Introduction}

Hepatocellular carcinoma (HCC) is the sixth most common neoplasm and the third most frequent cause of cancer mortality (1). Treatment strategy is determined based on liver function, number of tumors, tumor size, vascular invasion and extrahepatic metastases $(2,3)$. The first approach in the management of $\mathrm{HCC}$ is to determine if either hepatic resection or liver transplantation is feasible. As the majority of HCC cases develop in patients with cirrhosis, surgical interventions may become challenging. Patients with a small solitary tumor and very well preserved liver function are the best candidates for hepatic resection. Liver transplantation is most beneficial for patients who are not good candidates for resection, particularly those with Milan criteria (solitary tumor $\leq 5 \mathrm{~cm}$ and up to three nodules $\leq 3 \mathrm{~cm}$ ) (4); however, donor shortage greatly limits its applicability. Percutaneous ablation is the most frequently used treatment; however, its effectiveness is limited by tumor size and localization (5). In patients with multiple tumors without vascular invasion or extrahepatic metastases not amenable to curative treatments, chemoembolization may provide survival benefit. Findings of randomized trials of sorafenib have demonstrated survival benefits for patients with advanced $\mathrm{HCC}(6,7)$, suggesting that molecular-targeted therapies could be effective in this chemoresistant cancer.

Notable advances in surgical procedures and imaging modalities have improved the outcome of patients with HCC (8). However, the long-term prognosis remains unsatisfactory due to a high incidence of recurrence even after curative resection of $\mathrm{HCC}$, with a 5-year actuarial recurrence rate of $>80 \%$ (9-12). The main prognostic factors following hepatic resection for $\mathrm{HCC}$ include the stage of the cancer, vascular invasion, the number of tumors and liver function (5). As liver function correlates well with the degree of liver fibrosis $(13,14)$, there is a need to develop accurate and reliable noninvasive means to assess the severity of liver fibrosis. The aspartate aminotransferase to platelet ratio index (APRI) is a simple noninvasive index, and may be used to predict significant fibrosis and cirrhosis in patients with chronic hepatitis C (15-17). APRI was reported to predict postoperative prognosis for solitary small hepatitis B-related HCC (18). The 
present study aimed to analyze whether APRI could predict the prognosis following hepatic resection for HCC in general.

\section{Patients and methods}

Patient selection. The present retrospective study was approved by the Ethics Committee of The Jikei University School of Medicine (Tokyo, Japan). Between January 2000 and December 2011, 186 patients with HCC underwent hepatic resection at the Department of Surgery, Jikei University Hospital (Tokyo, Japan). Of these, 24 patients were excluded for the following reasons: A total of 11 patients had difficult pathological diagnosis due to complete necrosis by preoperative transcatheter arterial chemoembolization; 9 patients had additional procedures for other malignancies; 3 patients lost their lives due to other disease; and 1 patient did not have an indocyanine green test due to iodine allergy, leaving the remaining 162 patients for the present study. All patients underwent macroscopic curative resection for HCC. The patient characteristics are listed in Table I.

APRI was calculated as the ratio of [(aspartate aminotransferase/upper limit of normal value: $45 \mathrm{IU} / \mathrm{l} / \mathrm{platelet}$ counts $\left.\left(\times 10^{3} / \mu 1\right)\right] \times 100$. In general, the extent of hepatic resection was determined based on the retention rate of indocyanine green at $15 \mathrm{~min}$ (ICG-R15) before surgery (19). The type of resection was classified into two types: Anatomical resection (trisegmentectomy, extended lobectomy, lobectomy, segmentectomy or subsegmentectomy) and non-anatomical resection. The use of blood products and the dose were determined, as previously described (20). Tumor staging was based on the TNM stage classified by the Union for International Cancer Control (UICC) (21).

Univariate and multivariate analyses of disease-free and overall survival following hepatic resection, and clinicopathological factors. Initially, the relationship between clinicopathological variables and disease-free survival and overall survival following hepatic resection was investigated by univariate and multivariate analysis. The clinicopathological variables consisted of the following 15 factors: Age, sex, type of hepatitis virus, serum total bilirubin, serum albumin, prothrombin time (PT), ICG-R15, Child-Pugh classification (22), APRI, type of resection, surgery time, estimated blood loss, perioperative blood transfusion o f red cell concentrates (RCC), differentiation of tumor and TNM stage.

Determination of cut-off value of variables. Some clinicopathological continuous variables were classified into two groups for the log-rank test and the Cox proportional hazard regression models, as follows: Age, $<60$ or $\geq 60$ years; albumin, $\leq 3.5$ or $<3.5 \mathrm{~g} / \mathrm{dl}$; PT, $\leq 80$ or $>80 \%$; ICG-R $15,<15$ or $\geq 15 \%$, according to previous studies $(22,23)$; and serum total bilirubin, $<1.4$ or $\geq 1.4 \mathrm{mg} / \mathrm{dl}$, based on the normal limit in our facility. The median of variables in operative factors was classified as follows: Surgery time, $<360$ or $\geq 360 \mathrm{~min}$; and estimated blood loss, $<745$ or $\geq 745 \mathrm{ml}$. A cut-off value of APRI was determined by a receiver operating curve (ROC) of APRI, which was 0.45 .

Assessment of clinicopathological variables and APRI. The subjects were classified into two groups: APRI, $<0.45$ or $\geq 0.45$. Subsequently, patients' characteristics were analyzed in relation to APRI, using the following 18 factors: Age, sex, type of hepatitis virus, serum total bilirubin, serum albumin, PT\%, ICG-R15, Child-Pugh classification, type of resection, estimated blood loss, surgery time, perioperative blood transfusion of RCC, differentiation, liver cirrhosis and UICC TNM stage.

The recurrence of HCC was defined as newly detected hypervascular hepatic or extrahepatic tumors by ultrasonography, computed tomography, magnetic resonance image or angiography with or without increase in serum a-fetoprotein, or protein induced by vitamin $\mathrm{K}$ absence or antagonist-II. For recurrent HCC in the liver, repeated hepatic resection, local ablation therapy, transarterial chemoembolization or molecular target therapy (sorafenib) was given based on hepatic functional reserve judged mainly by ICG-R15. Extrahepatic recurrence was mainly treated conservatively, except for solitary lung metastasis or adrenal gland metastasis, provided that the primary HCC was controlled. In such a circumstance, limited partial resections were performed.

Statistical analysis. Data were expressed as the mean \pm standard deviation or median (minimum to maximum). Univariate analysis was performed using the non-paired Student's t-test and Chi-square test. Analysis of disease-free and overall survival was performed using the log-rank test. Factors that significantly influenced disease-free or overall survival were then used in the Cox proportional regression model for multivariate analysis. $\mathrm{P}<0.05$ was considered to indicate a statistically significant difference. The accuracy of APRI for pathological liver cirrhosis was determined by calculating the area under the curve from corresponding receiver curves (AUROC) using SPSS 17.0 for Windows, (SPSS. Inc., Chicago, IL, USA). The AUROC was expressed as plots of the test sensitivity vs. 1-speificity.

\section{Results}

Clinical patient characteristics. The background characteristics of the 162 patients are summarized in Table I. There were 138 men and 24 women. The median age was 63 years (range, 29-82 years). The majority of patients had hepatitis $C$ virus $(\mathrm{HCV})$ infection $(\mathrm{n}=64)$, followed by those without HCV or hepatitis $B$ virus (HBV) infection $(n=53)$ and those with HBV infection $(n=43)$. The majority of patients were in Child-Pugh grade A and liver damage grade A. The median APRI was 0.576 (range 0.101-5.918) and 70 patients (43.2\%) had the pathological diagnosis of liver cirrhosis.

Cut-off value of APRI using a ROC. A cut-off value of APRI was determined by a ROC of APRI, which predicted liver cirrhosis based on pathological diagnosis (Fig. 1). APRI yielded high AUROC with a level of 0.736 at a cut-off value of 0.45 (sensitivity, $0.829 ; 1$-specificity, 0.424 ).

Variables associated with overall and disease-free survival in univariate and multivariate analyses. Table II demonstrates the relationship between the clinicopathological variables and disease-free survival following hepatic resection for HCC. In univariate analysis, disease-free survival was significantly 
Table I. Patient characteristics.

\begin{tabular}{lcc}
\hline Factor & Ratio or median & Range \\
\hline Sex (male:female) & $138: 24$ & - \\
Age, years & 63 & $29-82$ \\
Virus type (NBNC:HBV:HCV:HBV+HCV) & $53: 43: 64: 2$ & - \\
Total bilirubin, mg/dl & 0.8 & $0.1-3.0$ \\
Albumin, g/dl & 3.9 & $2.5-5.0$ \\
Aspartate aminotransferase, IU/l & 38 & $8-261$ \\
Alanine aminotransferase, IU/l & 36 & $9-269$ \\
Platelet, x103/ $\mu$ l & 15.1 & $5.1-50.7$ \\
Prothrombin time, $\%$ & 90 & $54-100$ \\
Retention rate of indocyanine green at 15 min, $\%$ & 12 & $2-51$ \\
Child-Pugh (A:B) & $150: 12$ & - \\
Liver damage (A:B) & $124: 38$ & - \\
Aspartate aminotransferase to platelet ratio index & 0.58 & $0.101-5.918$ \\
Surgery (anatomical:partial) & $93: 69$ & - \\
Estimated blood loss, ml & 745 & $(0-25,770)$ \\
Surgery time, min & 365 & $100-1,030$ \\
Perioperative blood transfusion of red cell concentrates (present:absent) & - \\
Perioperative blood transfusion of fresh frozen plasma (present:absent) & $47: 115$ & - \\
Maximum diameter of tumor, cm & $55: 107$ & - \\
Number of tumors (solitary:multiple) & 3.5 & - \\
Vascular invasion (present:absent) & $132: 30$ & - \\
Differentiation (well or moderately:poorly) & $40: 122$ & - \\
Liver cirrhosis (present:absent) & $147: 15$ & - \\
Union for International Cancer Control & $70: 92$ & - \\
TNM classification (stage I:II:IIIA:IIIB:IIIC:IVB) & $99: 48: 7: 6: 1: 1$ & -
\end{tabular}

NBNC, negative for both markers of $\mathrm{HBV}$ and $\mathrm{HCV}$ infection (non-B, non-C); HCV, hepatitis C virus; HBV, hepatitis B virus.

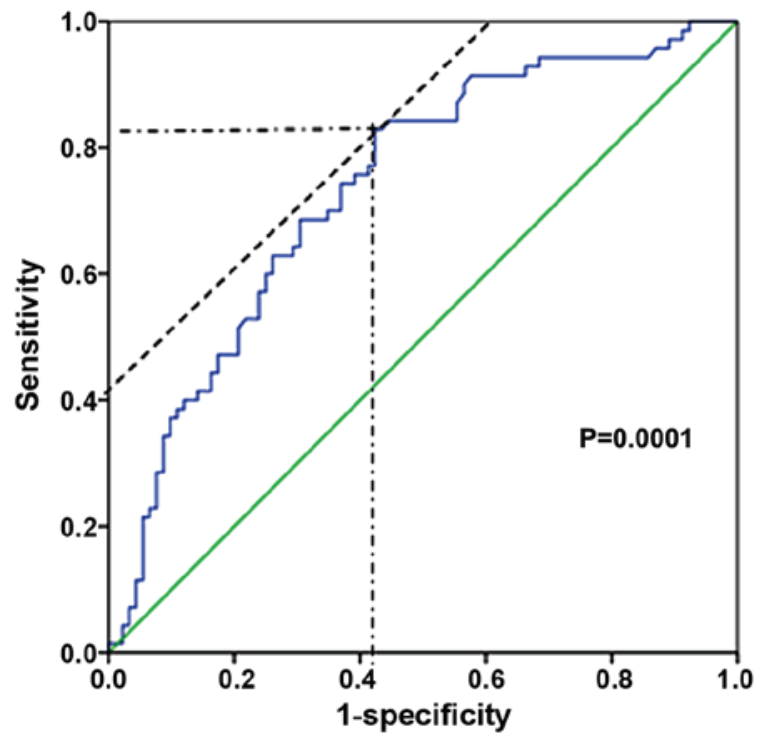

Figure 1. Receiver operating curve of aspartate aminotransferase to platelet ratio index for the prediction of liver cirrhosis. The blue line shows the receiver operating curve of aspartate aminotransferase to platelet ratio index. The green line shows the reference line. Cut-off, 0.45 ; sensitivity, 0.829 ; 1 -specificity, 0.424 ; area under receiver operating curve, $0.736 ; 95 \%$ confidence interval, 0.659-0.813; standard error, $0.039 ; \mathrm{P}=0.0001$. poor in patients with age $\geq 65$ years $(\mathrm{P}=0.0244)$, ICG-R15 $\geq 15 \%$ ( $\mathrm{P}=0.0043)$, APRI $\geq 0.45$ ( $\mathrm{P}=0.0216$; Fig. $2 \mathrm{~A})$, perioperative blood transfusion of RCC $(\mathrm{P}=0.0008)$, and TNM stage II, III or IV ( $\mathrm{P}=0.0076)$. In multivariate analysis, ICG-R15 $\geq 15 \%$ $(\mathrm{P}=0.0306)$, APRI $\geq 0.45(\mathrm{P}=0.0184)$, perioperative blood transfusion of RCC $(\mathrm{P}=0.0034)$, and TNM stage II, III or IV $(\mathrm{P}=0.0184)$ were independent and significant predictors of poor disease-free survival.

Table III demonstrates the relationship between the clinicopathological variables and overall survival following hepatic resection for HCC. In univariate analysis, overall survival was poor in patients with ICG-R $15 \geq 15 \%$ ( $\mathrm{P}=0.0084$ ), APRI $\geq 0.45$ ( $\mathrm{P}=0.0274$; Fig. $2 \mathrm{~B}$ ), perioperative blood transfusion of RCC $(\mathrm{P}=0.0002)$, and TNM stage II, III or IV $(\mathrm{P}=0.0003)$. In multivariate analysis, ICG-R15 $\geq 15 \%$ ( $\mathrm{P}=0.0454)$, APRI $\geq 0.45$ ( $\mathrm{P}=0.0417$ ), perioperative blood transfusion of RCC $(\mathrm{P}=0.0036)$, and TNM stage II, III or IV $(\mathrm{P}=0.0033)$ were independent and significant negative predictors.

Univariate analysis of patient characteristics in relation to APRI. Table IV demonstrates the relationship between clinicopathological variables and APRI. In univariate analysis, type of hepatitis virus ( $\mathrm{HCV}$ infection, $\mathrm{P}=0.002)$, liver function tests (serum total bilirubin, $\mathrm{P}=0.0044$; albumin, $\mathrm{P}=0.0002$; $\mathrm{PT} \%$, 
Table II. Univariate and multivariate analysis of disease-free survival following hepatic resection.

\begin{tabular}{|c|c|c|c|c|c|}
\hline \multirow[b]{2}{*}{ Factor } & \multirow[b]{2}{*}{$\begin{array}{c}\text { Patient } \\
\text { no. }\end{array}$} & \multicolumn{2}{|c|}{ Univariate analysis } & \multicolumn{2}{|c|}{ Multivariate analysis } \\
\hline & & $\begin{array}{l}\text { Hazard ratio } \\
(95 \% \mathrm{CI})\end{array}$ & P-value & $\begin{array}{l}\text { Hazard ratio } \\
(95 \% \mathrm{CI})\end{array}$ & P-value \\
\hline \multicolumn{6}{|l|}{ Age, years } \\
\hline$\geq 65$ & 73 & $1.606(1.063-2.427)$ & 0.0244 & $1.37(0.915-2.050)$ & 0.1263 \\
\hline$<65$ & 89 & & & & \\
\hline \multicolumn{6}{|l|}{ Sex } \\
\hline Male & 138 & $1.096(0.5981-2.007)$ & 0.7671 & - & - \\
\hline Female & 24 & & & & \\
\hline \multicolumn{6}{|l|}{ Hepatitis virus } \\
\hline $\mathrm{HCV}$ infection & 66 & $1.256(0.8377-1.883)$ & 0.27 & - & - \\
\hline Non-HCV infection & 96 & & & & \\
\hline \multicolumn{6}{|l|}{ Total bilirubin, mg/dl } \\
\hline$\geq 1.4$ & 9 & $2.008(0.7999-5.039)$ & 0.1377 & - & - \\
\hline$<1.4$ & 153 & & & & \\
\hline \multicolumn{6}{|l|}{ Albumin, g/dl } \\
\hline$\leq 3.5$ & 33 & $1.437(0.8660-2.386)$ & 0.1605 & - & - \\
\hline$>3.5$ & 129 & & & & \\
\hline \multicolumn{6}{|l|}{ Prothrombin time, $\%$} \\
\hline$>80$ & 129 & $1.522(0.8694-2.665)$ & 0.1415 & - & - \\
\hline$\leq 80$ & 33 & & & & \\
\hline \multicolumn{6}{|c|}{ Retention rate of indocyanine green at $15 \mathrm{~min}, \%$} \\
\hline$\geq 15$ & 67 & $1.876(1.219-2.889)$ & 0.0043 & $1.586(1.044-2.410)$ & 0.0306 \\
\hline$<15$ & 95 & & & & \\
\hline \multicolumn{6}{|l|}{ Child-Pugh } \\
\hline $\mathrm{B}$ & 12 & $2.124(0.9176-4.917)$ & 0.0785 & - & - \\
\hline A & 150 & & & & \\
\hline \multicolumn{6}{|c|}{ Aspartate aminotransferase to platelet ratio index } \\
\hline$\geq 0.45$ & 97 & $1.598(1.071-2.382)$ & 0.0216 & $1.692(1.093-2.620)$ & 0.0184 \\
\hline$<0.45$ & 65 & & & & \\
\hline \multicolumn{6}{|l|}{ Surgical procedure } \\
\hline Anatomical & 93 & $1.003(0.6753-1.491)$ & 0.9868 & - & - \\
\hline Non-anatomical & 69 & & & & \\
\hline \multicolumn{6}{|l|}{ Surgery time, $\min$} \\
\hline$\geq 360$ & 82 & $1.274(0.8522-1.903)$ & 0.238 & - & - \\
\hline$<360$ & 80 & & & & \\
\hline \multicolumn{6}{|l|}{ Estimated blood loss, $\mathrm{g}$} \\
\hline$\geq 745$ & 81 & $1.417(0.9524-2.109)$ & 0.0856 & - & - \\
\hline$<745$ & 81 & & & & \\
\hline \multicolumn{6}{|c|}{ Perioperative blood transfusion of red cell concentrates } \\
\hline Present & 47 & $2.257(1.404-3.628)$ & 0.0008 & $1.875(1.231-2.857)$ & 0.0034 \\
\hline Absent & 115 & & & & \\
\hline \multicolumn{6}{|l|}{ Differentiation } \\
\hline Well or moderate & 147 & $1.062(0.5238-2.154)$ & 0.8669 & - & - \\
\hline Poor & 15 & & & & \\
\hline \multicolumn{6}{|c|}{ Union for International Cancer Control Stage } \\
\hline $\mathrm{I}$ & 99 & $1.783(1.166-2.727)$ & 0.0076 & $1.637(1.087-2.465)$ & 0.0184 \\
\hline II, III or IV & 63 & & & & \\
\hline
\end{tabular}

CI, confidence interval; $\mathrm{HCV}$, hepatitis $\mathrm{C}$ virus. 
Table III. Univariate and multivariate analysis of overall survival following hepatic resection.

\begin{tabular}{|c|c|c|c|c|c|}
\hline \multirow[b]{2}{*}{ Factor } & \multirow[b]{2}{*}{$\begin{array}{c}\text { Patient } \\
\text { no. }\end{array}$} & \multicolumn{2}{|c|}{ Univariate analysis } & \multicolumn{2}{|c|}{ Multivariate analysis } \\
\hline & & $\begin{array}{l}\text { Hazard ratio } \\
(95 \% \mathrm{CI})\end{array}$ & P-value & $\begin{array}{l}\text { Hazard ratio } \\
(95 \% \mathrm{CI})\end{array}$ & P-value \\
\hline \multicolumn{6}{|l|}{ Age, years } \\
\hline$\geq 65$ & 73 & $1.520(0.8026-2.880)$ & 0.1987 & - & - \\
\hline$<65$ & 89 & & & & \\
\hline \multicolumn{6}{|l|}{ Sex } \\
\hline Male & 138 & $2.007(0.7824-5.148)$ & 0.1472 & - & - \\
\hline Female & 24 & & & & \\
\hline \multicolumn{6}{|l|}{ Hepatitis virus } \\
\hline HCV infection & 66 & $1.317(0.6969-2.492)$ & 0.7155 & - & - \\
\hline Non-HCV infection & 96 & & & & \\
\hline \multicolumn{6}{|l|}{ Total bilirubin, mg/dl } \\
\hline$\geq 1.4$ & 9 & $1.381(0.3641-5.2236)$ & 0.6353 & - & - \\
\hline$<1.4$ & 153 & & & & \\
\hline \multicolumn{6}{|l|}{ Albumin, g/dl } \\
\hline$\leq 3.5$ & 33 & $1.561(0.6987-3.488)$ & 0.2776 & - & - \\
\hline$>3.5$ & 129 & & & & \\
\hline \multicolumn{6}{|l|}{ Prothrombin time, $\%$} \\
\hline$>80$ & 129 & $2.078(0.8750-4.936)$ & 0.0974 & - & - \\
\hline$\leq 80$ & 33 & & & & \\
\hline \multicolumn{6}{|c|}{ Retention rate of indocyanine green at $15 \mathrm{~min}, \%$} \\
\hline$\geq 15$ & 67 & $2.460(1.260-4.804)$ & 0.0084 & $1.966(1.014-3.813)$ & 0.0454 \\
\hline$<15$ & 95 & & & & \\
\hline \multicolumn{6}{|l|}{ Child-Pugh } \\
\hline $\mathrm{B}$ & 12 & $3.252(0.8717-12.13)$ & 0.0792 & - & - \\
\hline A & 150 & & & & \\
\hline \multicolumn{6}{|c|}{ Aspartate aminotransferase to platelet ratio index } \\
\hline$\geq 0.45$ & 97 & $2.054(1.083-3.896)$ & 0.0274 & $2.239(1.031-4.862)$ & 0.0417 \\
\hline$<0.45$ & 65 & & & & \\
\hline \multicolumn{6}{|l|}{ Surgical procedure } \\
\hline Anatomical & 93 & $1.859(0.9857-3.505)$ & 0.0554 & - & - \\
\hline Non-anatomical & 69 & & & & \\
\hline \multicolumn{6}{|l|}{ Surgery time, $\min$} \\
\hline$\geq 360$ & 82 & $1.000(0.5297-1.889)$ & 0.9994 & - & - \\
\hline$<360$ & 80 & & & & \\
\hline \multicolumn{6}{|l|}{ Estimated blood loss, $\mathrm{g}$} \\
\hline$\geq 745$ & 81 & $1.764(0.9402-3.309)$ & 0.0771 & - & - \\
\hline$<745$ & 81 & & & & \\
\hline \multicolumn{6}{|c|}{ Perioperative blood transfusion of red cell concentrates } \\
\hline Present & 47 & $3.679(1.801-7.519)$ & 0.0002 & $2.607(1.366-4.974)$ & 0.0036 \\
\hline Absent & 115 & & & & \\
\hline \multicolumn{6}{|l|}{ Differentiation } \\
\hline Well or moderate & 147 & $2.237(0.7414-6.752)$ & 0.153 & - & - \\
\hline Poor & 15 & & & & \\
\hline \multicolumn{6}{|c|}{ Union for International Cancer Control stage } \\
\hline $\mathrm{I}$ & 99 & $3.366(1.732-6.542)$ & 0.0003 & $2.738(1.399-5.358)$ & 0.0033 \\
\hline II, III or IV & 63 & & & & \\
\hline
\end{tabular}

$\mathrm{CI}$, confidence interval; $\mathrm{HCV}$, hepatitis $\mathrm{C}$ virus. 
Table IV. Univariate analysis of patient characteristics in relation to APRI.

\begin{tabular}{|c|c|c|c|}
\hline \multirow[b]{2}{*}{ Factor } & \multicolumn{2}{|c|}{ APRI } & \multirow[b]{2}{*}{ Univariate P-value } \\
\hline & $\geq 0.45(\mathrm{n}=97)$ & $<0.45(\mathrm{n}=65)$ & \\
\hline Sex (male:female) & $82: 15$ & $56: 9$ & 0.7763 \\
\hline Age, years & $63 \pm 9$ & $60 \pm 13$ & 0.0524 \\
\hline \multicolumn{4}{|l|}{ Virus type } \\
\hline (NBNC:HBV:HCV:HBV+HCV) & $21: 27: 48: 1$ & $32: 16: 16: 1$ & 0.0015 \\
\hline HCV:non-HCV & $49: 48$ & $17: 48$ & 0.0020 \\
\hline Total bilirubin, mg/dl & $0.9 \pm 0.4$ & $0.8 \pm 0.3$ & 0.0044 \\
\hline Albumin, g/dl & $3.8 \pm 0.4$ & $4.0 \pm 0.4$ & 0.0002 \\
\hline Prothrombin time, $\%$ & $87 \pm 10$ & $93 \pm 8$ & $<0.0001$ \\
\hline Retention rate of indocyanine green at $15 \mathrm{~min}, \%$ & $16 \pm 9$ & $12 \pm 7$ & 0.0005 \\
\hline Child-Pugh (A:B) & $87: 10$ & $63: 2$ & 0.0849 \\
\hline Type of resection (anatomical:non-anatomical) & $50: 47$ & $43: 22$ & 0.0653 \\
\hline Estimated blood loss, $\mathrm{ml}$ & $1,478 \pm 2,853$ & $1,409 \pm 2,280$ & 0.8707 \\
\hline Surgery time, $\min$ & $358 \pm 144$ & $398 \pm 174$ & 0.1558 \\
\hline Perioperative blood transfusion of red cell concentrates (present:absent) & $27: 70$ & $20: 45$ & 0.6867 \\
\hline Differentiation (well or moderate:poor) & $88: 9$ & $59: 6$ & 0.9918 \\
\hline Liver cirrhosis (present:absent) & $58: 39$ & $12: 53$ & $<0.0001$ \\
\hline Union for International Cancer Control stage (I:II, III or IV) & $60: 37$ & $39: 26$ & 0.8123 \\
\hline
\end{tabular}

APRI, aspartate aminotransferase to platelet ratio index; NBNC, negative for both markers of HBV and HCV infection (non-B, non-C); HCV, hepatitis $\mathrm{C}$ virus; $\mathrm{HBV}$, hepatitis B virus.

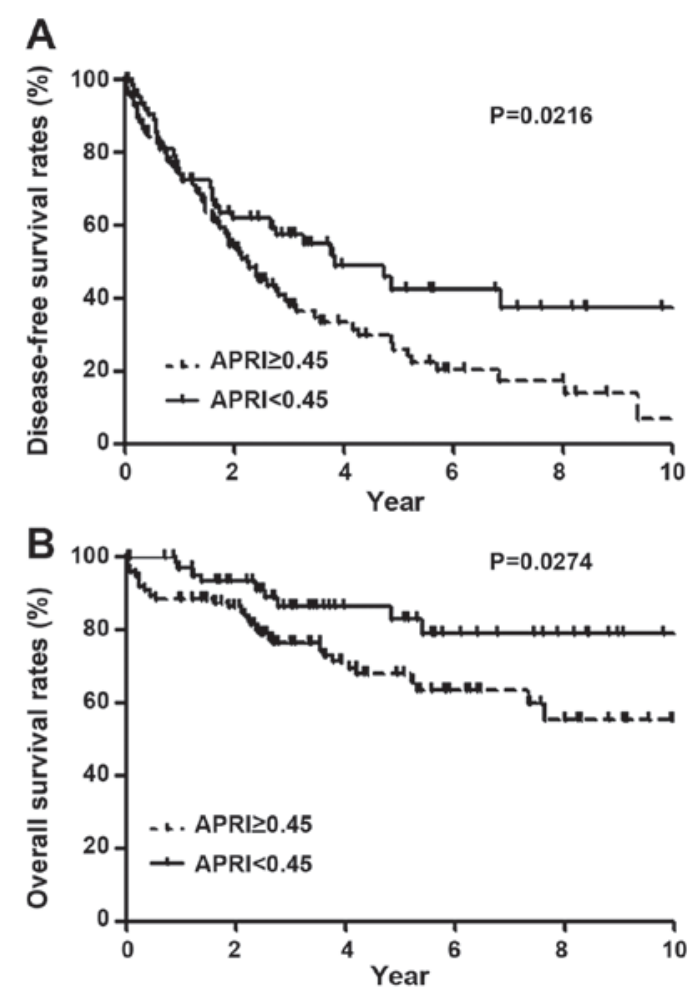

Figure 2. Disease-free and overall survival following hepatic resection for hepatocellular carcinoma in relation to APRI. Higher APRI values were associated with significantly worse (A) disease-free and (B) overall survival. The significant differences in disease-free survival and overall survival were observed after 2 years and immediately after hepatic resection, respectively. APRI, aspartate aminotransferase to platelet ratio index.
$\mathrm{P}<0.0001$; ICG-R15, $\mathrm{P}=0.0005)$, and pathology-proven liver cirrhosis $(\mathrm{P}<0.0001)$ were positively associated with APRI. Age $(\mathrm{P}=0.0524)$, type of resection $(\mathrm{P}=0.0653)$, and Child $\mathrm{Pugh}$ classification $(\mathrm{P}=0.0849)$ demonstrated a trend toward a positive association with APRI; however, these were not significant.

\section{Discussion}

Histological examination by biopsy remains an important diagnostic modality to estimate the degree of liver fibrosis (24). Although percutaneous liver biopsy is, in general, a safe procedure, it is costly and does carry a small risk of complication (25). Therefore, it is difficult to perform liver biopsy for all preoperative patients with liver diseases. In addition, sampling error may occur as only $1 / 50,000$ of the whole liver is sampled. Furthermore, inter- and intra-observer discrepancies of $10-20 \%$ in assessing hepatic fibrosis have been reported, which may lead to the misunderstanding of cirrhosis (26-28). Therefore, the development of noninvasive markers of liver fibrosis is a clinical and research priority.

Some noninvasive indices, such as the amino-terminal propeptide of collagen III, hyaluronic acid, Fibrotest, Fibrometer test, Hepascore and FibroScan (transient elastography or liver stiffness), have been introduced to assess the degree of fibrosis (29). However, these tests usually require special and costly equipment for daily practice. On the other hand, APRI is a simple, noninvasive index derived from routine blood tests, and correlates significantly with the stage of fibrosis, with a higher correlation coefficient than platelet count, or aspartate aminotransferase level alone, because it 
amplifies the opposing effects of liver fibrosis on aspartate aminotransferase and platelet count (15). Although APRI is a promising index with limited expense and widespread availability, it has never been reported as a prognostic factor of patients with HCC following hepatic resection except in one report, in which APRI was advocated to predict postoperative outcome in patients with solitary small hepatitis B-related HCC (18). The cut-off value of APRI in their report was 0.47 , which was very similar to the value in the present study of 0.45 . On the other hand, a difference was the patient criteria: The present study was applied to operable patients with HCC regardless of type of hepatitis virus, but the previous report was limited to solitary and small hepatitis B-related HCC (18).

In patients with HCC, the incidence of concomitant liver cirrhosis is much higher than chronic hepatitis, regardless of type of hepatitis virus (30-32). Depending on the etiology of liver cirrhosis, the lifetime risk for the development of HCC is as high as $80 \%$ in patients with liver cirrhosis (3). Therefore, noninvasive fibrosis markers may be an important predictor of HCC occurrence. In the present study, the difference in disease-free survival is clearer later than 2 years after hepatic resection. Then, this difference is due to multicentric occurrence of $\mathrm{HCC}$ because intrahepatic recurrence via vascular invasion generally occurs in the early period compared with multicentric recurrence (9). The present study suggested that APRI is a predictor of multicentric recurrence. Other significant factors associated with overall or disease-free survival on multivariate analysis were ICG-R15, TNM stage and perioperative blood transfusion of RCC, which were consistent with other reports $(10,20,33-35)$.

In the present study, higher APRI values had a positive association with the ratio of $\mathrm{HCV}$ infection. A meta-analysis of patients undergoing hepatic resection for HCC demonstrated that preoperative liver function, such as AST, platelet count and Child-Pugh classification was worse in the HCV-HCC group than in either the HBV-HCC or negative for both markers of HBV and HCV infection [non-B, non-C (NBNC)]-HCC group (36). The prevalence of liver cirrhosis was the highest in the HCV-HCC group, followed by the HBV-HCC group and the NBNC-HCC group (36). Therefore, the ratio of HCV infection may be higher in the group of APRI $\geq 0.45$ than APRI $<0.45$.

There are several limitations in the present study. First, this is a retrospective study. It was not possible to compare the APRI to other noninvasive indices, including the amino-terminal propeptide of collagen III, hyaluronic acid, FibroTest, FibroMeter test, Hepascore and Fibroscan (transient elastography for liver stiffness). Second, the number of patients who underwent hepatic resection was small, and so validation for the survival rate following hepatic resection by using the value of APRI could not be performed. To confirm the influence of APRI on survival following hepatic resection, more case numbers or prospective studies are required.

In conclusion, the present study suggests that APRI derived from routine blood tests appears to be a significant predictive factor of overall and disease-free survival following hepatic resection for $\mathrm{HCC}$.

\section{Acknowledgements}

Not applicable.

\section{Funding}

No funding was received.

\section{Availability of data and materials}

The datasets used and/or analyzed during the current study are available from the corresponding author on reasonable request.

\section{Authors' contributions}

The all authors conducted surgery and perioperative management for patients, MM, SW, KH and HS contributed to the clinical data analysis. MM and KY wrote the manuscript. All authors read and approved the final manuscript.

\section{Ethics approval and consent to participate}

Appropriate ethical approval was obtained from the Institutional Review Board of The Jikei University School of Medicine (Tokyo, Japan). Patient consent was not required for the present study as it was conducted retrospectively.

\section{Patient consent for publication}

Not applicable.

\section{Competing interests}

The authors declare that they have no competing interests.

\section{References}

1. Ferlay J, Shin HR, Bray F, Forman D, Mathers C and Parkin DM: Estimates of worldwide burden of cancer in 2008: GLOBOCAN 2008. Int J Cancer 127: 2893-2917, 2010.

2. Reig M, Darnell A, Forner A, Rimola J, Ayuso C and Bruix J: Systemic therapy for hepatocellular carcinoma: The issue of treatment stage migration and registration of progression using the BCLC-refined RECIST. Semin Liver Dis 34: 444-455, 2014.

3. Forner A, Llovet JM and Bruix J: Hepatocellular carcinoma. Lancet 379: 1245-1255, 2012.

4. Mazzaferro V, Regalia E, Doci R, Andreola S, Pulvirenti A, Bozzetti F, Montalto F, Ammatuna M, Morabito A and Gennari L: Liver transplantation for the treatment of small hepatocellular carcinomas in patients with cirrhosis. N Engl J Med 334: 693-699, 1996.

5. Clinical Practice Guidelines for Hepatocellular Carcinoma-The Japan Society of Hepatology 2009 update. Hepatol Res 40 (Suppl 1): S2-S144, 2010.

6. Llovet JM, Ricci S, Mazzaferro V, Hilgard P, Gane E, Blanc JF, de Oliveira AC, Santoro A, Raoul JL, Forner A, et al: Sorafenib in advanced hepatocellular carcinoma. N Engl J Med 359: 378-390, 2008.

7. Cheng AL, Kang YK, Chen Z, Tsao CJ, Qin S, Kim JS, Luo R, Feng J, Ye S, Yang TS, et al: Efficacy and safety of sorafenib in patients in the Asia-Pacific region with advanced hepatocellular carcinoma: A phase III randomised, double-blind, placebo-controlled trial. Lancet Oncol 10: 25-34, 2009.

8. Takayama T, Makuuchi M, Hirohashi S, Sakamoto M, Yamamoto J, Shimada K, Kosuge T, Okada S, Takayasu K and Yamasaki S: Early hepatocellular carcinoma as an entity with a high rate of surgical cure. Hepatology 28: 1241-1246, 1998.

9. Imamura H, Matsuyama Y, Tanaka E, Ohkubo T, Hasegawa K, Miyagawa S, Sugawara Y, Minagawa M, Takayama T, Kawasaki S and Makuuchi M: Risk factors contributing to early and late phase intrahepatic recurrence of hepatocellular carcinoma after hepatectomy. J Hepatol 38: 200-207, 2003. 
10. Poon RT, Ng IO, Fan ST, Lai EC, Lo CM, Liu CL and Wong J: Clinicopathologic features of long-term survivors and disease-free survivors after resection of hepatocellular carcinoma: A study of a prospective cohort. J Clin Oncol 19: 3037-3044, 2001.

11. Poon RT, Fan ST, Lo CM, Liu CL and Wong J: Intrahepatic recurrence after curative resection of hepatocellular carcinoma: Long-term results of treatment and prognostic factors. Ann Surg 229: 216-222, 1999.

12. Yamamoto J, Kosuge T, Takayama T, Shimada K, Yamasaki S, Ozaki H, Yamaguchi N and Makuuchi M: Recurrence of hepatocellular carcinoma after surgery. Br J Surg 83: 1219-1222, 1996.

13. Kusaka K, Harihara Y, Torzilli G, Kubota K, Takayama T, Makuuchi M, Mori M and Omata S: Objective evaluation of liver consistency to estimate hepatic fibrosis and functional reserve for hepatectomy. J Am Coll Surg 191: 47-53, 2000.

14. Kumazawa K, Edamoto Y, Yanase M and Nakayama T: Liver analysis using gadolinium-ethoxybenzyl-diethylenetriamine pentaacetic acid-enhanced magnetic resonance imaging: Correlation with histological grading and quantitative liver evaluation prior to hepatectomy. Hepatol Res 42: 1081-1088, 2012.

15. Wai CT, Greenson JK, Fontana RJ, Kalbfleisch JD, Marrero JA Conjeevaram HS and Lok AS: A simple noninvasive index can predict both significant fibrosis and cirrhosis in patients with chronic hepatitis C. Hepatology 38: 518-526, 2003.

16. Lin ZH, Xin YN, Dong QJ, Wang Q, Jiang XJ, Zhan SH, Sun Y and Xuan SY: Performance of the aspartate aminotransferase-to-platelet ratio index for the staging of hepatitis C-related fibrosis: An updated meta-analysis. Hepatology 53: 726-736, 2011.

17. Shaheen AA and Myers RP: Diagnostic accuracy of the aspartate aminotransferase-to-platelet ratio index for the prediction of hepatitis C-related fibrosis: A systematic review. Hepatology 46: 912-921, 2007.

18. Hung HH, Su CW, Lai CR, Chau GY, Chan CC, Huang YH, Huo TI, Lee PC, Kao WY, Lee SD and Wu JC: Fibrosis and AST to platelet ratio index predict post-operative prognosis for solitary small hepatitis B-related hepatocellular carcinoma. Hepatol Int 4: 691-699, 2010.

19. Miyagawa S, Makuuchi M, Kawasaki S and Kakazu T: Criteria for safe hepatic resection. Am J Surg 169: 589-594, 1995.

20. Shiba H, Ishida Y, Wakiyama S, Iida T, Matsumoto M Sakamoto T, Ito R, Gocho T, Furukawa K, Fujiwara Y, et al: Negative impact of blood transfusion on recurrence and prognosis of hepatocellular carcinoma after hepatic resection. J Gastrointest Surg 13: 1636-1642, 2009.

21. Edge SB and Compton CC: The American Joint Committee on Cancer: The 7th edition of the AJCC cancer staging manual and the future of TNM. Ann Surg Oncol 17: 1471-1474, 2010.

22. Pugh RN, Murray-Lyon IM, Dawson JL, Pietroni MC and Williams R: Transection of the oesophagus for bleeding oesophageal varices. Br J Surg 60: 646-649, 1973.

23. Minagawa M, Ikai I, Matsuyama Y, Yamaoka $Y$ and Makuuchi M: Staging of hepatocellular carcinoma: Assessment of the Japanese TNM and AJCC/UICC TNM systems in a cohort of 13,772 patients in Japan. Ann Surg 245: 909-922, 2007.

24. Chevallier M, Guerret S, Chossegros P, Gerard F and Grimaud JA: A histological semiquantitative scoring system for evaluation of hepatic fibrosis in needle liver biopsy specimens: Comparison with morphometric studies. Hepatology 20: 349-355, 1994.
25. Cadranel JF, Rufat P and Degos F: Practices of liver biopsy in France: Results of a prospective nationwide survey. For the group of epidemiology of the French association for the study of the liver (AFEF). Hepatology 32: 477-481, 2000.

26. Regev A, Berho M, Jeffers LJ, Milikowski C, Molina EG, Pyrsopoulos NT, Feng ZZ, Reddy KR and Schiff ER: Sampling error and intraobserver variation in liver biopsy in patients with chronic HCV infection. Am J Gastroenterol 97: 2614-2618, 2002.

27. Westin J, Lagging LM, Wejstål R, Norkrans G and Dhillon AP Interobserver study of liver histopathology using the Ishak score in patients with chronic hepatitis C virus infection. Liver 19: 183-187, 1999.

28. Intraobserver and interobserver variations in liver biopsy interpretation in patients with chronic hepatitis C. The French METAVIR cooperative study group. Hepatology 20: 15-20, 1994

29. Shiha G, Sarin SK, Ibrahim AE, Omata M, Kumar A, Lesmana LA, Leung N, Tozun N, Hamid S, Jafri W, et al: Liver fibrosis: Consensus recommendations of the Asian pacific association for the study of the liver (APASL). Hepatol Int 3: 323-333, 2009.

30. Nishiguchi S, Kuroki T, Nakatani S, Morimoto H, Takeda T, Nakajima S, Shiomi S, Seki S, Kobayashi K and Otani S: Randomised trial of effects of interferon-alpha on incidence of hepatocellular carcinoma in chronic active hepatitis $\mathrm{C}$ with cirrhosis. Lancet 346: 1051-1055, 1995.

31. Liaw YF and Chu CM: Hepatitis B virus infection. Lancet 373: 582-592, 2009.

32. Kawaguchi T, Kakuma T, Yatsuhashi H, Watanabe H, Saitsu H, Nakao K, Taketomi A, Ohta S, Tabaru A, Takenaka K, et al: Data mining reveals complex interactions of risk factors and clinical feature profiling associated with the staging of non-hepatitis B virus/non-hepatitis $C$ virus-related hepatocellular carcinoma. Hepatol Res 41: 564-571, 2011.

33. Yamamoto J, Kosuge T, Takayama T, Shimada K, Yamasaki S, Ozaki H, Yamaguchi N, Mizuno S and Makuuchi M: Perioperative blood transfusion promotes recurrence of hepatocellular carcinoma after hepatectomy. Surgery 115: 303-309, 1994.

34. Fujimoto J, Okamoto E, Yamanaka N, Tanaka T and Tanaka W: Adverse effect of perioperative blood transfusions on survival after hepatic resection for hepatocellular carcinoma. Hepatogastroenterology 44: 1390-1396, 1997.

35. Poon RT, Fan ST, Lo CM, Liu CL, Lam CM, Yuen WK, Yeung C and Wong J: Improving perioperative outcome expands the role of hepatectomy in management of benign and malignant hepatobiliary diseases: Analysis of 1222 consecutive patients from a prospective database. Ann Surg 240: 698-710, 2004.

36. Zhou Y, Si X, Wu L, Su X, Li B and Zhang Z: Influence of viral hepatitis status on prognosis in patients undergoing hepatic resection for hepatocellular carcinoma: A meta-analysis of observational studies. World J Surg Oncol 9: 108, 2011.

This work is licensed under a Creative Commons Attribution-NonCommercial-NoDerivatives 4.0 International (CC BY-NC-ND 4.0) License. 